\title{
MATHEMATICAL MODELS: PLANNING TOOLS FOR THE GREAT LAKES ${ }^{1}$
}

\author{
Sam B. Upchurch and David C. N. Robb ${ }^{2}$
}

\begin{abstract}
The Great Lakes Basin Commission has initiated a Framework Study to assess the present and projected water- and related land-resource problems and demands in the Great Lakes Basin. Poorly defined objectives; incomplete and inconsistent data arrays; unknown air, biota, water, and sediment interactions; and multiple planning considerations for interconnected, large lake systems hinder objective planning. To incorporate mathematical modeling as a planning tool for the Great Lakes, a two-phase program, comprising a feasibility and design study followed by contracted and in-house modeling, data assembly, and plan development, has been initiated. The models will be used to identify sensitivities of the lakes to planning and management alternatives, insufficiencies in the data base, and inadequately understood ecosystem interactions. For the first time objective testing of resource-utilization plans to identify potential conflicts will provide a rational and costeffective approach to Great Lakes management. Because disciplines will be interrelated, the longterm effects of planning alternatives and their impacts on neighboring lakes and states can be evaluated. Testing of the consequences of environmental accidents and increased pollution levels can be evaluated, and risks to the resource determined. Examples are cited to demonstrate the use of such planning tools.

(KEY TERMS: Great Lakes; simulation; water-resource planning; Great Lakes Basin Commission; limnological systems analysis; phosphates; chlorides)
\end{abstract}

\section{INTRODUCTION}

There is a great need for objective, rapid appraisal of trends, planning alternatives, and priority assignments to deal with Great Lakes water-resource problems, such as excessive organic production due to waste nutrient discharge, introduction of toxic wastes, and competition for limited resources by interests with conflicting goals; and to expedite regional coordination and planning by local, state, and federal authorities. The Great Lakes Basin Commission, which consists of representatives of the eight Great Lakes states and the federal agencies that have interests in Great Lakes water resources, was created by Presidential order under authority of the Water Resources Planning Act (P.L. 89-80) for such coordination and planning.

The Great Lakes Basin Commission has initiated a Type I Framework Study to assess the present and projected water-resource demands and problems in the Great Lakes Basin. In the early stages of the Framework Study it was determined that conventional planning techniques, when applied to the Great Lakes, are not as effective as desired. Several obstacles were identified that hinder objective consideration of planning alternatives for Great Lakes resource

\footnotetext{
${ }_{2}^{1}$ Paper No. 72031 of the Water Resources Bulletin. Discussions are open until October 1, 1972.

${ }^{2}$ Respectively, Assistant Professor of the Department of Geology, Michigan State University, East Lansing, Michigan 48823; and Comprehensive Basin Planner of the Great Lakes Basin Commission, Ann Arbor, Michigan 48108 .
} 
development. The most important of these obstacles include poorly defined goals and objectives; an incomplete and inconsistent data base; insufficient knowledge of water circulation; unknown interactions among the biota, water, and sediment; and the multiplicity of processes that must be considered when planning for an interconnected system of large lakes.

Therefore, there is a demand for an objective system for assessing the consequences of planning alternatives for the Great Lakes. The first stage in the development of such a system must be the identification of gaps in the data base, unknown fundamental relationships, and large-scale interactions of physical, chemical, and biological processes. In 1969 the Great Lakes Basin Commission initiated a feasibility program to determine which level of mathematical simulation might best aid in evaluating the effects of proposed management strategies on the Great Lakes. A two-phase program was developed, which consists of (I) a combination feasibility and design study, currently being performed under contract, and (II) based on the findings of the feasibility-design study, a comprehensive program that will include contracted modeling, in-house modeling and data assembly by Basin Commission member agencies, and water-resource plan development. The Phase II program is intended to provide a framework for future, coordinated model development.

\section{PHASE I-PRELIMINARY MODEL DESIGN}

The preliminary model design phase will identify those physical, chemical, and biological interactions that can be modeled, specify the required data base and variables, and suggest priorities for development of the models. For those water-resource problems that cannot be immediately addressed by simulation, the Phase I study will indicate the requirements to obviate the restriction.

Several potential problems are being explored in Phase I. The primary problems lie in insufficient data for complete verification of the models in some disciplines, a lack of knowledge of fundamental relationships, and an absence of social, economic, and demographic data for socio-economic objective functions. It is intended that shortcomings identified in the Phase I effort will be defined in the Phase II model development. Subsequent modeling efforts will be directed to expansion and improvement of data collection efforts in the Great Lakes Basin and in the lakes proper, incorporation of drainage basin models, and inclusion of socioeconomic functions. Provisions for these expansions will be made in the Phase I design, through the development of an administrative model for subsystem model interfacing and through avoidance of "black box" models, whenever possible.

Although mathematical models are being developed and used by the Great Lakes Basin Commission member states and agencies, the Phase I study contract was awarded to an environmental engineering consulting firm in order to insure minimum design bias and equitable assessment of planning objectives, data validity, and program relevance. A board of technical advisors, consisting of Great Lakes and systems specialists in biology, hydrology/ hydraulics, and geochemistry, has been retained to advise the Basin Commission staff and the contractor on the technical aspects of the program. The contractor has been directed to perform a series of evaluations; suggest feasible goals and objectives in the light of the needs of the Commission's member agencies; develop a conceptual plan of model development, priorities, and interfacing; identify data gaps and critical variables; and develop a small, pilot model to demonstrate the applicability of modeling to the problems of the Great Lakes and assist in evaluating sensitivities of the system to variable selection. The evaluations to be made include: (1) priorities of water-resource problems, (2) applicability of variables, (3) data availability and compatibility, (4) relevant time scales, and (5) applicability of existing models and algorithms. 
The problems that have been identified to date are manifold and will require multiple models, interfaced through a logical framework so that member states and agencies can interrelate regional and functional dependencies. A few of the more critical problems that will be addressed in the program are listed in Table 1. Variables selected to address these problems can be classified as to functional relevance, and include (1) hydrodynamic, hydrological, and meteorological; (2) physical; (3) geomorphological; (4) energy; (5) organic chemical; (6) inorganic chemical; (7) biological; and (8) radiological variables. The pilot model will show, in a simplistic manner, interactions between problem-related processes and phytoplankton production for a selected region.

TABLE 1. Representative Great Lakes Water-Resource Problems by Use

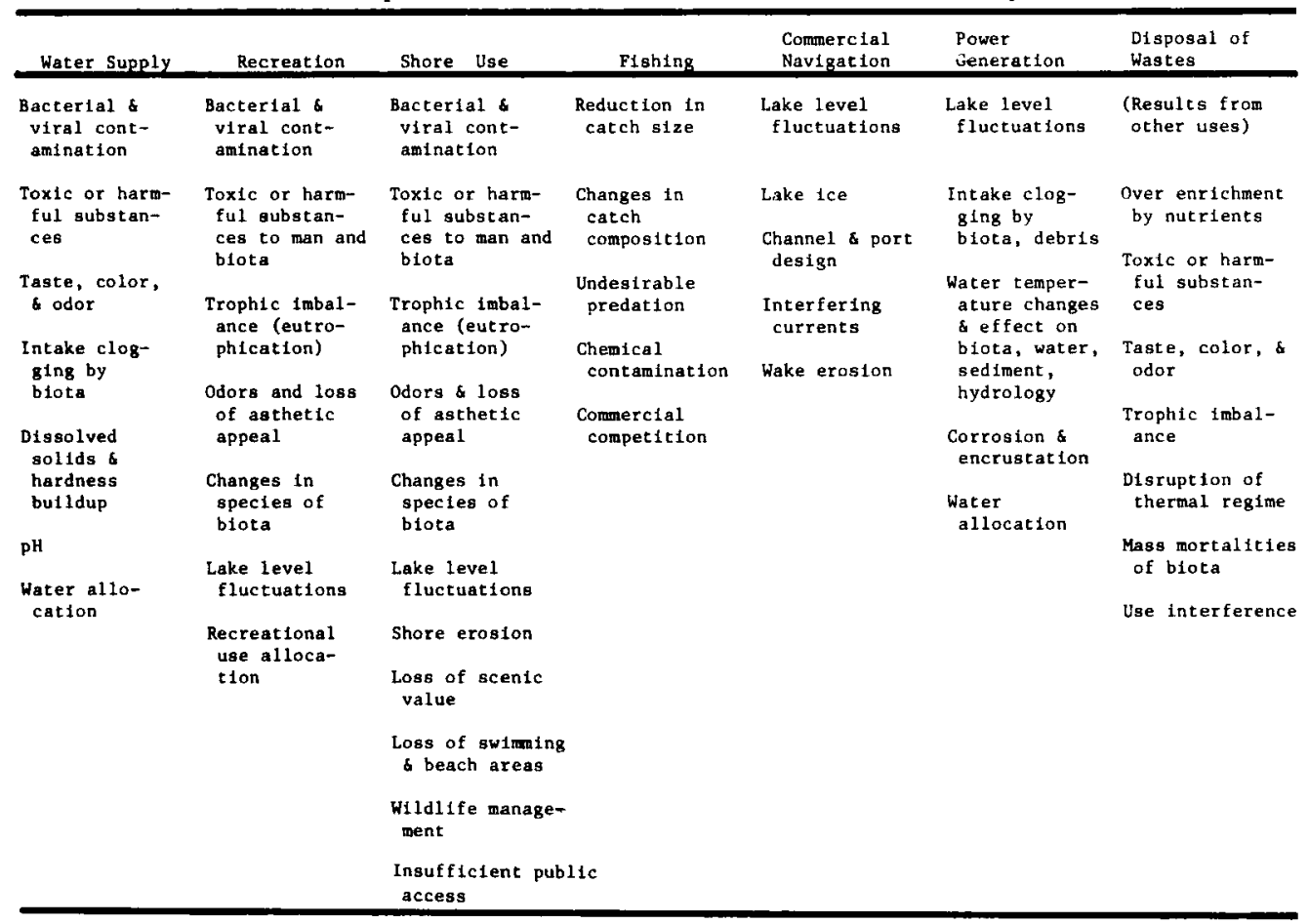

\section{PHASE II-PRIMARY MODEL DEVELOPMENT}

Subject to modifications as the result of the Phase I program, the main modeling program is projected to consist of adaptation, modification, and development of existing programs; development of the administrative framework; development of new, in-house and contracted models to address specific problems; and data assembly and reduction for use in model verification and sensitivity analysis. The models selected for use in the Phase II modeling efforts will be identified on the basis of applicability to regional planning, and suitability for use by the member states and agencies for operational planning. The initial models to be developed specifically for the Phase II program will be regional in scope and broad in design in order to interrelate the various lakes and their responses to interstate and state-wide plans. Input sources (tributaries, waste outfalls, diversions, etc.) will be considered as point sources, and no attempt will be made to incorporate socio-economic factors in the models, although the input/output variables will reflect socio-economic influences. Time scales selected will vary 
according to needs. Short-term response models for local areas and for specific disciplines will be largely the responsibility of the member states and agencies, although the long-term regional consequences of the local plans will be tested through the Basin Commission's regional planning models.

The models will yield several important results. For the first time there will be objective testing of many different resource utilization plans in order to point out potential conflicts and provide for a more rational and cost-effective approach to Great Lakes resource management. Because disciplines will be interrelated at the planning level, current and projected planning alternatives will be evaluated as to long-term effects and impacts on "downstream" lakes and neighboring states. Regional testing of the consequences of environmental accidents and increased pollution levels and evaluation of risks to the resources will be possible.

\section{IMPACT ON MODELS ON REGIONAL PLANNING}

There are no regional models for the Great Lakes system that interrelate the physical, chemical, and biological processes in the lakes or the system. With current trends of increasing population and per capita resource demands, with the recognition that the ecosystem should be preserved and managed, and with the trend toward preservation of the resource while allowing maximum use, there must be a system by which the contemplated actions by resource users can be evaluated in terms of the inter- and intralake effects on the resource. The availability of such a system will enable planners to provide decision makers with greatly improved information on proposed levels of use and treatment and their potential consequences.

One major problem in developing models for resource planning is the tendency to model at too great a level of detail. This process results in unnecessary complexity and expense in the model development, testing and exercising stages. It also imposes heavy expenses because of data requirements. Equally as important, it may literally bury the planner and the decision maker under so much information that he finds it very difficult to evaluate the model output. Models of any type, and especially resource planning models, should be no more complex than required to provide the necessary information.

An example of a very simple back-mix chemical budget model, developed to investigate the responses of the five Great Lakes to chemical loading alternatives, follows. Although the chemical budget model is not representative of the complexity or comprehensiveness of the models to be developed, the model is of interest because it illustrates the need for consideration of inflow and outflow from and to other lakes, the need for consideration of lake volumes and hydrology, and the utility of models of minimum complexity to evaluate planning problems.

The model consists of iterations over yearly increments of the equation

$$
\Sigma L_{(R, P, G, D, S, B)_{j, t}}+L_{O_{j-1, t}}-\Sigma L_{(O, E, D, G, S, B)_{j, t}}+L_{L k_{j, t-1}}=L_{L k_{j, t}} .
$$

$L$ is the mass (load) of a chemical constituent present in the lake $(L k)$ or introduced to or removed from the lake by runoff $(R)$, precipitation $(P)$, groundwater $(G)$, diversions $(D)$, sediment interaction $(S)$, biota $(B)$, outflow $(O)$, and evaporation $(E)$. The subscript $j$ refers to the lake in question, so $L_{O}$ refers to the load introduced from the lake "upstream" from the lake under consideration. The subscript $t$ refers to the year of the iteration.

At the present time, the above equation can be solved only for conserved constituents. Load estimates for the contributions to each lake from upper lakes, runoff, and precipitation 
have been calculated from the lake chemical data of Weiler and Chawla [1969], precipitation chemical data of Junge and Werby [1958] and Gorham [1961], and analyses from tributary water quality stations (Figure 1). In order to test alternative treatment levels the loads must be separated into natural and cultural components, which can be done from historical data [Upchurch, 1971] or from comparison of soil and bedrock composition to tributary composition on the respective drainage basins [Upchurch, in press]. The estimated natural, background loads and total loads for chlorides are given in Table 2.

Chlorides, which are assumed to be conservative in the Great Lakes, have been used to estimate response times and flushing times for several of the Great Lakes [Ownbey and Willeke, 1965; Ownbey and Kee, 1967; Rainey, 1967; Rodin, 1969; Sweers, 1969; O'Connor and Mueller, 1970]. With the exception of O'Connor and Mueller [1970], none of these studies considered fluctuations in the hydrologic cycle or responses of the lakes to changes in loading in upstream lakes. Since chlorides do appear to be conservative, the chemical budget model described above can be used to test these variations. Sediment interactions and biotic assimilation can be assumed to be zero and groundwater exchange is assumed to be negligible, although chloride inflows through the lake bottoms from the extensive salt deposits under the Michigan structural basin are likely. With these assumptions the model indicates lake response times to treatment levels, pollution load increases, and abatement contingencies. For example, owing to the large volumes of the lakes as compared to their inflows, the present concentrations in the lakes do not reflect present loading conditions. The lag time between reaching a specific loading condition and the adjustment of the lakes to those loads can be shown by

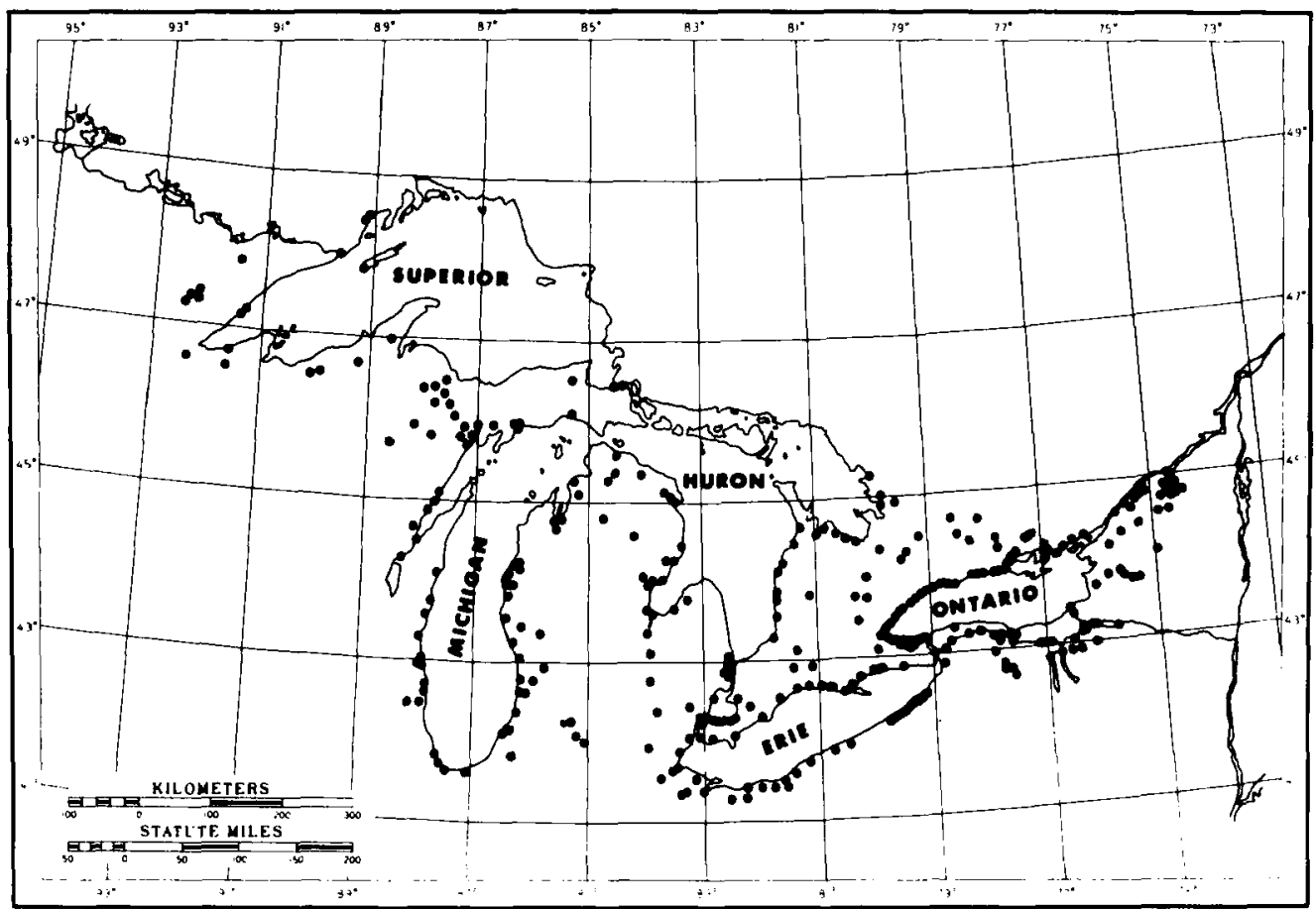

Fig. 1. Location of water quality stations used to estimate chemical loading in the Great Lakes. Estimated loads from regions where there are no stations are discussed in the text. Station data are from the U.S. Geological Survey and the Ontario Water Resources Commission. 
TABLE 2. Estimated Chloride Loads in the Great Lakes, in $10^{8}$ Kilograms per Year ${ }^{1}$

\begin{tabular}{|c|c|c|c|c|c|}
\hline $\begin{array}{l}\text { Load } \\
\text { Condition } \\
\end{array}$ & $\begin{array}{l}\text { Lake } \\
\text { Superior }\end{array}$ & $\begin{array}{l}\text { Lake } \\
\text { Michigan } \\
\end{array}$ & $\begin{array}{l}\text { Lake } \\
\text { Huron }\end{array}$ & $\begin{array}{l}\text { Lake } \\
\text { Erie } \\
\end{array}$ & $\begin{array}{l}\text { Lake } \\
\text { Ontario }\end{array}$ \\
\hline $\begin{array}{l}\text { Estimated Natural } \\
\text { Background } \mathrm{Cl}^{-} \\
\text {load }\end{array}$ & 1.1 & 2.2 & 4.0 & 8.7 & $\underline{2 /}$ \\
\hline $\begin{array}{l}\text { Estimated total } \\
\mathrm{C} 1 \text { load in } 1968\end{array}$ & 1.1 & 8.2 & 17.0 & 39.0 & 29.0 \\
\hline $\begin{array}{l}\text { Estimated } \mathrm{Cl}^{-} \\
\text {load after } 80 \% \\
\text { removal of cultural } \\
\mathrm{Cl}^{-} \text {contribution }\end{array}$ & 1.1 & 2.8 & 6.6 & 15.0 & 5.9 \\
\hline $\begin{array}{l}\text { Estimated } \mathrm{Cl}^{-} \text {load } \\
\text { after } 80 \% \text { removal } \\
\text { of cultural } \mathrm{Cl} \\
\text { contribution } \\
\text { southern Lake Michi- } \\
\text { gan metropolitan area } \\
\text { Detroit, Toledo, \& } \\
\text { Cleveland }\end{array}$ & 1.1 & 4.1 & 17.0 & 18.0 & 29.0 \\
\hline
\end{tabular}

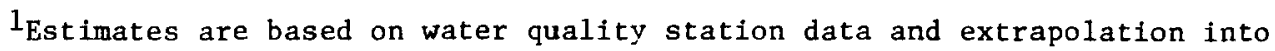
sparse data areas through comparison with soil and bedrock composition.

${ }^{2}$ The chloride load in Lake ontario is so low that it is masked by inflow from Lake Erie and cannot be calculated.
}

starting the model with present concentrations in the lakes and loading conditions (Figure 2). In all cases it will take in excess of one hundred years to reach a steady-state condition where chloride inflow into each lake is equaled by outflow. Under current loadings, initial and predicted steady-state concentrations $(\mathrm{mg} / \mathrm{l})$ and percent increases are: Superior-1.3, 1.6, 21; Michigan-6.3, 17.4, 176; Huron-6.2, 15.5, 146; Erie-24.6, 34.5, 40; Ontario-27.5, 44.1, 60. Clearly, Lakes Erie and Ontario reflect the influence of cultural inflow more than the upper Great Lakes. This is due to the fact that they are small in comparison to the upper lakes, sustain larger populations, and receive chemical loads from upstream lakes as well as their own basins. Thus, water quality impairment and awareness of it is greater in Lakes Ontario and Erie, and abatement action has therefore been initiated. Lakes Huron and Michigan are equally endangered, but since the lakes do not yet reflect current loads little regional abatement action has resulted.

The Enforcement Conferences held by the states and federal government and the International Joint Commission (1969) have recommended an 80 percent reduction in phosphate loading for Lake Michigan and the lower lakes. In light of the slow response times of the lakes to loading conditions, it is appropriate to ask how the lakes might respond with time to partial and complete achievement of the recommended 80 percent reduction of the culturally-derived part of the phosphate load. Exercise of the conservative, chloride model yields some insights.

If 80 percent reduction of the chloride influx from the southern Lake Michigan metropolitan area, the Detroit metropolitan area, and from Toledo and Cleveland is achieved, the response of the lakes will be immediate (Figure 3). Projected initial and final concentrations $(\mathrm{mg} / \mathrm{l})$ and percent changes are: Superior-1.3, 1.6, +23; Michigan-6.3, 8.7, +38; Huron-6.2, 


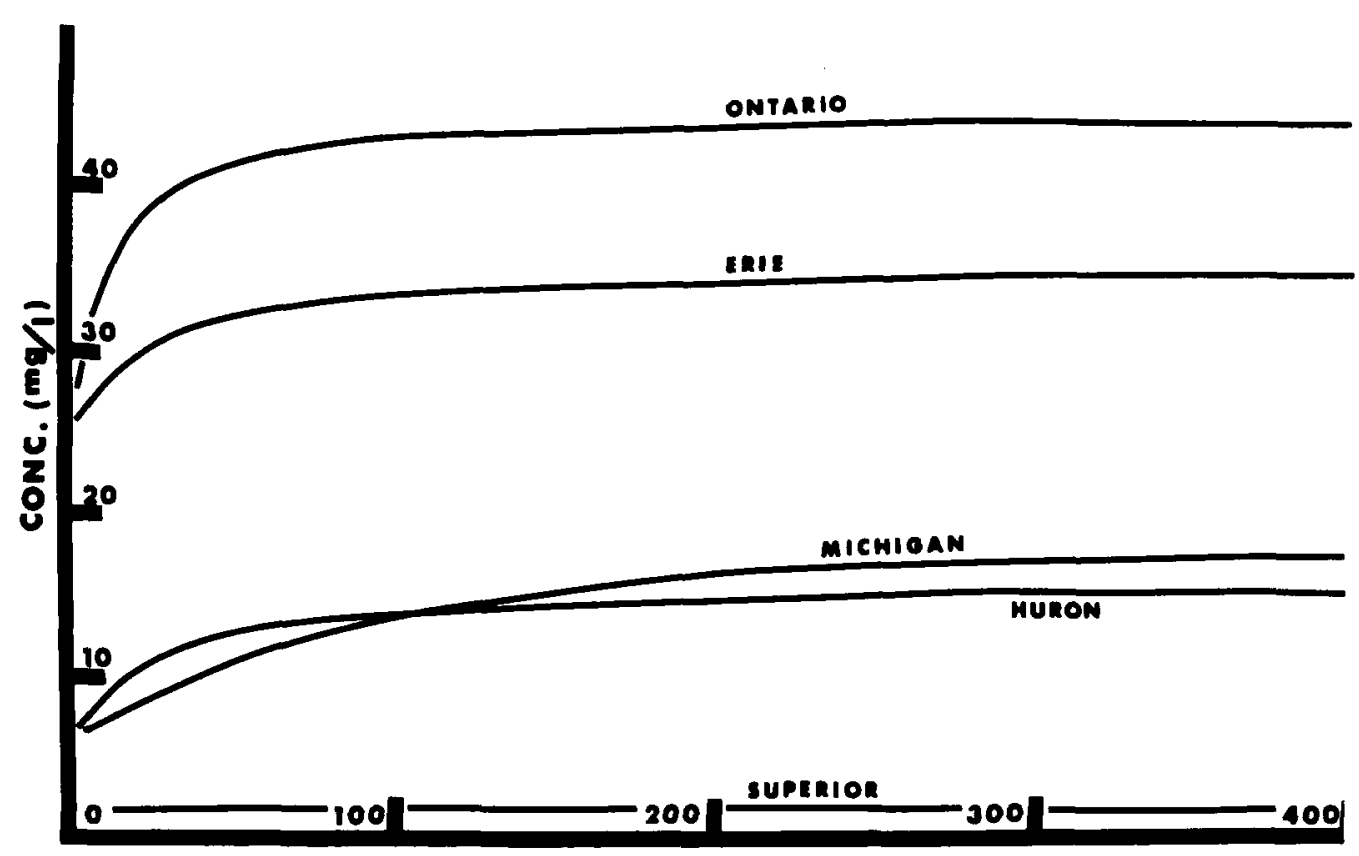

YEARS

Fig. 2. Projected chloride buildup in the Great Lakes starting with 1968 concentrations [Weiler and Chawla, 1969] and continuing loading at the 1968 loading rate (Table 2).

13.0, +110; Erie-24.6, 21.0, -15; Ontario-27.5, 32.3, +17. Lake Erie will show an immediate improvement in water quality and the steady-state concentrations of Lakes Michigan, Huron, and Ontario will be greater than present concentrations but less than the concentrations if nothing is done (Figure 2). However, owing to the interaction between the lakes, as the quality of Lakes Huron and Michigan deteriorates, Lake Erie will again be subjected to increased loads, and its quality will deteriorate. If $80 \%$ removal is achieved for all cultural input into the lakes, the water quality of the lakes will improve (Figure 4). Projected initial and final concentrations $(\mathrm{mg} / \mathrm{l})$ and percent change are: Superior-1.3, 1.6, +23 ; Michigan-6.3, 6.0, -5; Huron-6.2, 6.1, -2; Erie-24.6, 13.4, -46; Ontario-27.5, 14.5, -47.

Again, owing to the fact that the lakes do not reflect present loading conditions, reductions in the final steady-state concentrations will not be as great as desired. Lakes Erie and Ontario will be improved by about 50 percent and Lakes Michigan and Huron will remain at present levels.

The times required to achieve the results depicted and the ultimate concentrations are based on the assumption of an absence of interaction between the constituent and the biota or lake sediment. In the case of a nonconservative constituent, such as a nutrient, retention times in the lakes will usually be greater due to release from the sediment and flow through the food chain. Therefore, the chlorides data represent the minimum expected responses in terms of lake concentration to the phosphate management alternatives considered. The model can be used to test the regional response of the lakes to nutrient loading, although response times cannot be estimated in the absence of knowledge on the kinetics of sediment and biotic interactions. The data of Beeton and Moffat [1964] and unpublished data from the National 


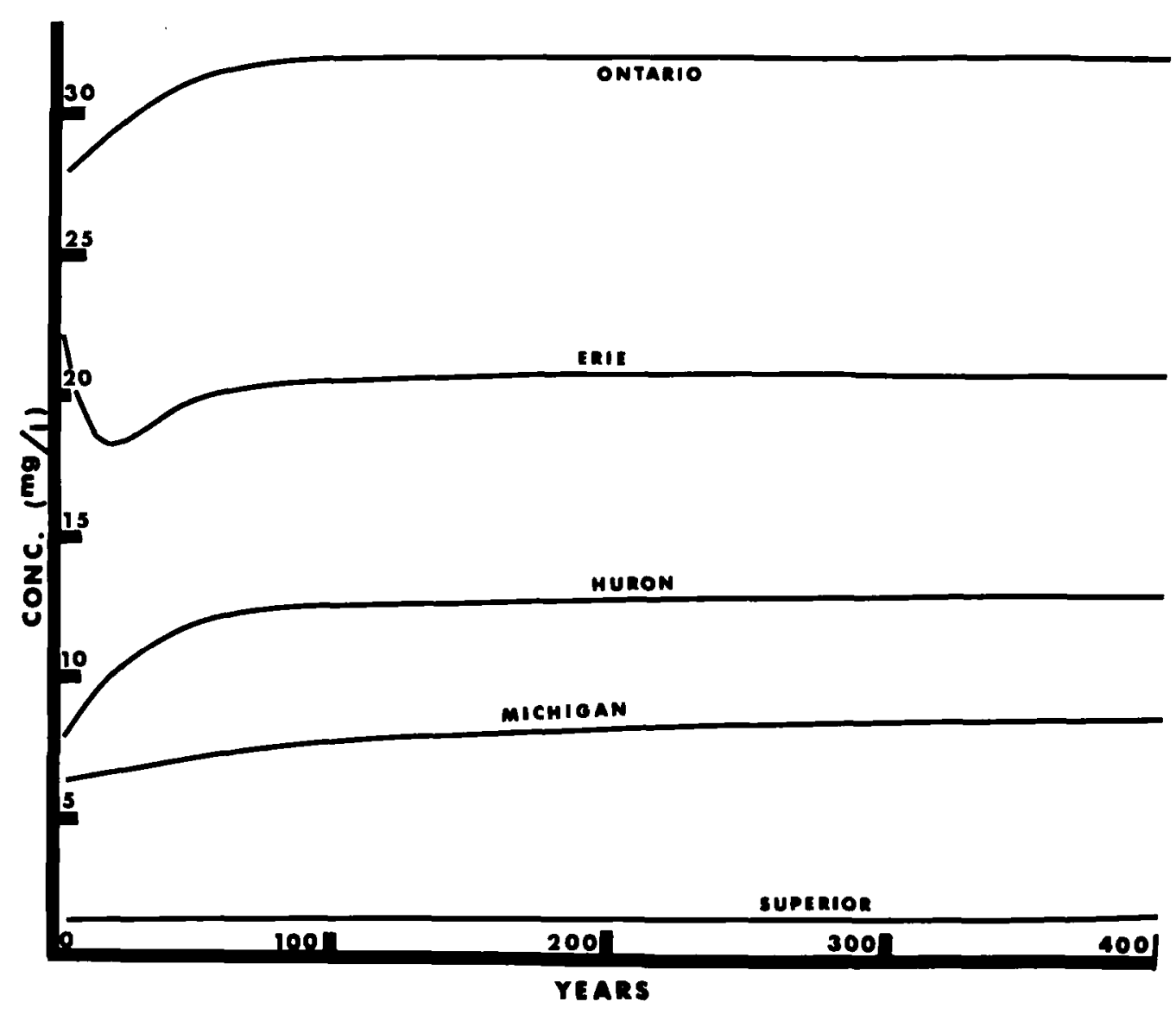

Fig. 3. Projected chloride buildup in the Great Lakes starting with 1968 concentrations [Weiler and Chawla, 1969] and cutting the cultural part of the 1968 chloride load by $80 \%$ at the ChicagoMilwaukee complex, Detroit, Toledo, and Cleveland (see Table 2).

Oceanic and Atmospheric Administration [Upchurch, in press] show phosphate concentration gradients that decrease to the range from $0.005 \mathrm{mg} / \mathrm{l}$ to 0 phosphate in the upper lakes and to $0.025 \mathrm{mg} / \mathrm{l}$ in Lake Ontario. Therefore, with the exception of Lake Erie, phosphorus assimilation in each lake is essentially complete, and there is little transfer of phosphorus from one lake to another. Estimates of the limiting concentration of phosphorus for plant growth vary [Greeson, 1969], but $0.005 \mathrm{mg} / \mathrm{l}$ seems to be a reasonable level to stabilize plant production in the Great Lakes because it is within the range of concentrations considered to be limiting and because that concentration recurs throughout the lake system where nutrient loading and plant production are minimal. Thus, under ideal conditions, a steady-state concentration should be maintained where inflow into the lake should be no more than that removed at a concentration of $0.005 \mathrm{mg} / 1$ and any excess usable phosphorus over the $0.005 \mathrm{mg} / 1$ limit will go into plant production. Table 3 summarizes current estimated phosphate loads derived by the estimation procedure described for chlorides, the phosphate loads that would result if 80 percent removal is effected, and the loads if a concentration of $0.005 \mathrm{mg} / 1$ is to be maintained. Clearly, with the exception of Lake Ontario, 80 percent treatment is insufficient to maintain 


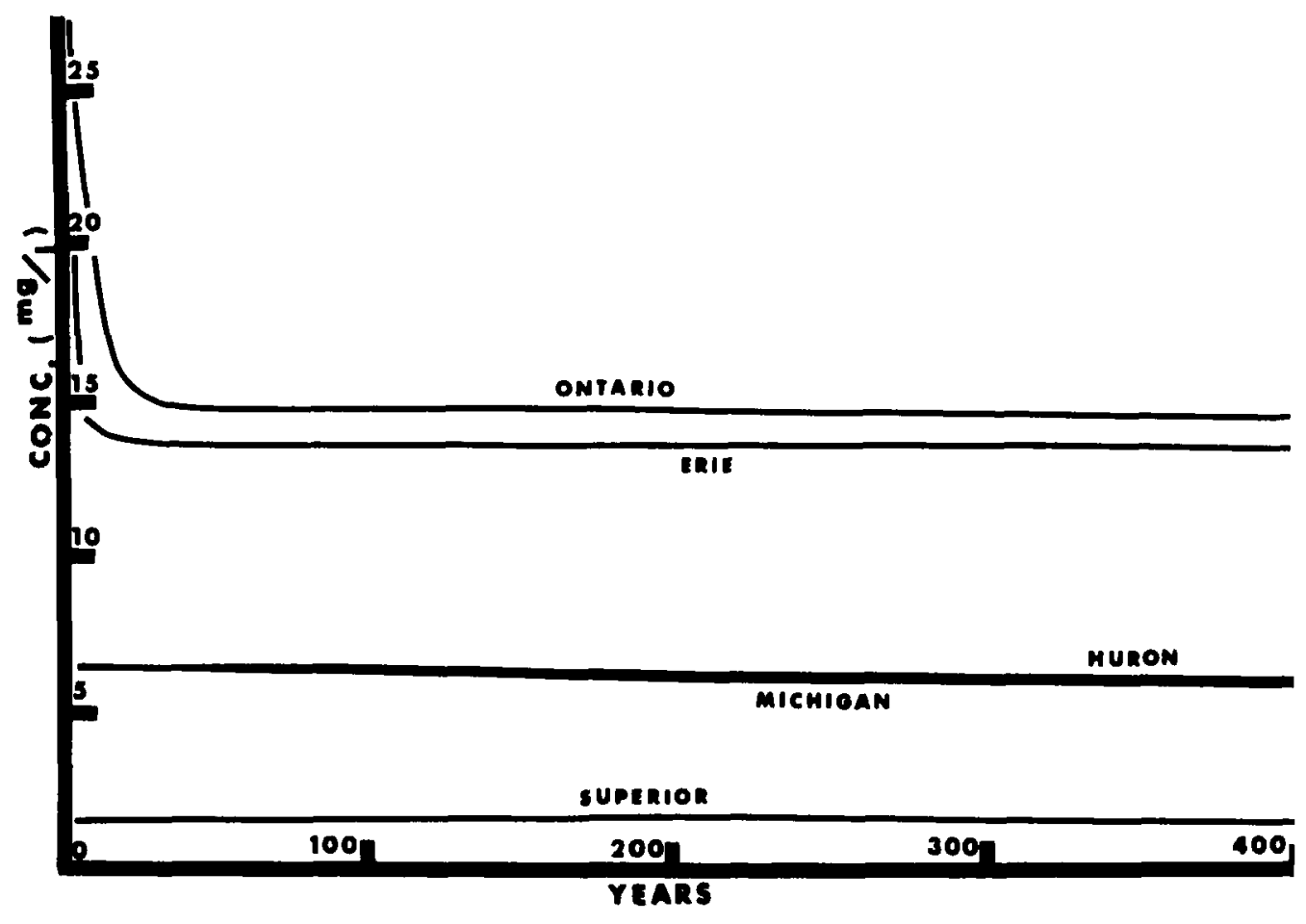

Fig. 4. Projected chloride buildup in the Great Lakes starting with 1968 concentrations [Weiler and Chawla, 1969] and cutting the cultural part of the 1968 chloride load by $80 \%$ throughout the Great Lakes Basin (Table 2).

that concentration; treatment levels must be in excess of 90 percent. With population growth, loss from uncontrollable sources, and release from the biota and sediment, even higher levels of treatment will be required.

The chloride and phosphate models point out two of the advantages of considering the lakes as an interconnected system in a time framework. First, the impact of "upstream" lakes on those below can be evaluated, and planning alternatives can be adjusted to accommodate the totality of the system. Secondly, evaluations of changes in the quality of the system, which is slow to reflect ecological stresses, can be made and the future of the lake system predicted, based on present resource uses. In the cases cited there is good evidence that considering the lakes individually and using present water quality for selection of treatment levels will not yield realistic conclusions about the feasibility of proposed programs to achieve the restoration of the quality of the lakes. More sophisticated single constituent models and models that incorporate a multiplicity of physical, chemical, and biological responses are bound to yield much more insight into the system and allow better planning for a more cost-effective management of the Great Lakes resources.

\section{CONCLUSIONS}

A major step in regional planning for the Great Lakes is underway. Based on the findings of the Great Lakes Basin Commission's combined feasibility and design study, a series of 
TABLE 3. Estimated Great Lakes Phosphate Loads in Kilograms per Year

\begin{tabular}{|c|c|c|c|c|c|}
\hline & $\begin{array}{l}\text { Lake } \\
\text { Superior }\end{array}$ & $\begin{array}{l}\text { Lake } \\
\text { Michigan } \\
\end{array}$ & $\begin{array}{l}\text { Lake } \\
\text { Huron } \\
\end{array}$ & $\begin{array}{l}\text { Lake } \\
\text { Erie } \\
\end{array}$ & $\begin{array}{l}\text { Lake } \\
\text { Ontario } \\
\end{array}$ \\
\hline $\begin{array}{c}\text { Estimated current } \\
\text { phosphate loads }\end{array}$ & $4.3 \times 10^{6}$ & $1.1 \times 10^{7}$ & $1.0 \times 10^{7}$ & $6.7 \times 10^{7}$ & $2.6 \times 10^{6}$ \\
\hline $\begin{array}{l}\text { Load upon } 80 \% \\
\text { reduction }\end{array}$ & $1.3 \times 10^{6}$ & $2.2 \times 10^{6}$ & $2.0 \times 10^{6}$ & $1.3 \times 10^{7}$ & $5.3 \times 10^{5}$ \\
\hline $\begin{array}{l}\text { Load required to } \\
\text { maintain lake } \\
\text { concentrations } \\
\text { at } 0.005 \mathrm{mg} / 1 \\
\text { phosphates }\end{array}$ & $3.3 \times 10^{5}$ & $2.3 \times 10^{5}$ & $8.3 \times 10^{5}$ & $9.3 \times 10^{5}$ & $1.1 \times 10^{6}$ \\
\hline $\begin{array}{l}\text { Required percent } \\
\text { reduction of input } \\
\text { to maintain a maxi- } \\
\text { mum of } 0.005 \mathrm{mg} / 1 \\
\text { phosphates. }\end{array}$ & 92 & 98 & 92 & 99 & $60^{3 /}$ \\
\hline
\end{tabular}

\footnotetext{
$1_{\text {Upchurch, in press. }}$

2 Based on the assumption that essentially all phosphate is assimilated in each lake and maximum allowable input is that required to maintain inflow equal to outflow.

360 percent phosphate reduction is required if phosphate influx from Lake Erie ceases. However, at present rate of phosphate addition to Lake Ontario from Lake Erie (estimated $4.0 \times 10^{7} \mathrm{~kg} / \mathrm{yr}$ ) 97 percent reduction of total introduced phosphate is required. Since the phosphate contribution from the Lake ontario basin is only $7 \%$ of the inflow from Lake Erie, load reduction in Lake Erie has to be accomplished.
}

models spanning those physical, chemical, and biological processes for which there are sufficient data and knowledge of the fundamental relationships will be developed. The models will consist of two types. First there will be a series of broad scale, regional models to interface disciplines and regions. These models will serve as a communications mechanism for the Great Lakes Basin Commission member agencies and states and other interested parties and as a subsystem model interfacing device. The second type of model will be developed through member agency in-house and contracted work, and will serve in a planning role for operational development of the Great Lakes water resources by the respective agencies. The input-output variables of the two types of models will be compatible so that agencies can investigate the effects of their contemplated actions on other disciplines by interacting through the broader, administrative models.

A simple, back mixed, chemical budget model for the Great Lakes demonstrates the utility of modeling to present planning problems. Perturbation of the model leads to several conclusions and suggests a need for comprehensive, regional simulation models for planning.

Because of their volume as compared to inflows, the response times of the Great Lakes are much too long (on the order of 100 years) to allow a cut and try approach to resource management. The need for rational, productive models for evaluating resource management strategies thus becomes obvious. Such models offer relatively inexpensive means of rationally assessing the potential consequences-both positive and negative-of contemplated resource management strategies on the Great Lakes. Important additional benefits of modeling include insight as to the adequacy of the available data base and current levels of understanding of the basic relationships among the physical, chemical, and biological systems in the Lakes. 
Modeling also forces a rational and detailed consideration of problems, needs, goals, and objectives for resource management.

\section{LITERATURE CITED}

Beeton, A. M. and J. W. Moffett. 1964. Lake Michigan chemical data, 1954-55, 1960-61. Data Rept. 6, Fish and Wildlife Serv., Bureau of Comm. Fisheries, U.S. Dept. of Interior. 100 pp.

Gorham, E. 1961. Factors influencing supply of major ions to inland waters, with special reference to the atmosphere. Geological Soc. of America Bull., 72:795-840.

Greeson, P. E. 1969. Lake eutrophication-a natural process. Water Resources Res., 5:16-30.

International Joint Commission. 1969. Report on the pollution of Lake Erie, Lake Ontario, and the international section of the St. Lawrence River. Washington, D.C.

Junge, C. E. and R. T. Werbey. 1958. The concentration of chloride, sodium, sodium, and sulfate in rain water over the United States. Jour. Meteorology, 15:417-425.

O'Connor, D. J. and J. A. Mueller. 1970. A water quality model of chlorides in Great Lakes. Jour. Sanitary Eng., S4A:955-975.

Ownbey, C. R. and D. A. Kee. 1967. Chlorides in Lake Erie. Proc. 10th Conf. on Great Lakes Res., pp. 382-389.

Ownbey, C. R. and G. E. Willeke. 1965. Long-term solids buildup in Lake Michigan water. Proc. 8th Conf. on Great Lakes Res. Great Lakes Research Inst., Univ. of Michigan. Pub. 15, pp. 141-152.

Rainey, R. H. 1967. Natural displacement of pollution from the Great Lakes. Science, 155:1242-1243.

Rodin, E. Y. 1969. Behavior of nonconservative pollutants in aqueous environments. Jour. Water Poll. Control Fed., 41:R475-R481.

Sweers, H. E. 1969. Removal of contaminants from Lake Ontario by natural processes. Proc. 12 th Conf. on Great Lakes Res., pp. 734-741.

Upchurch, S. B. 1971. Natural weathering and pollution in the Great Lakes. Mich. Earth Scien tist, JanuaryMarch, pp. 6-9.

Upchurch, S. B. In press. Chemical characteristics of the Great Lakes. Great Lakes Basin Comm. Comprehensive Framework Study Appendix 4, Limnology of Lakes and Embayments, Ch. VII.

Weiler, H. R. and V. K. Chawla. 1969. Dissolved mineral quality of Great Lakes waters. Proc. 12th Conf. on Great Lakes Res., pp. 801-818. 